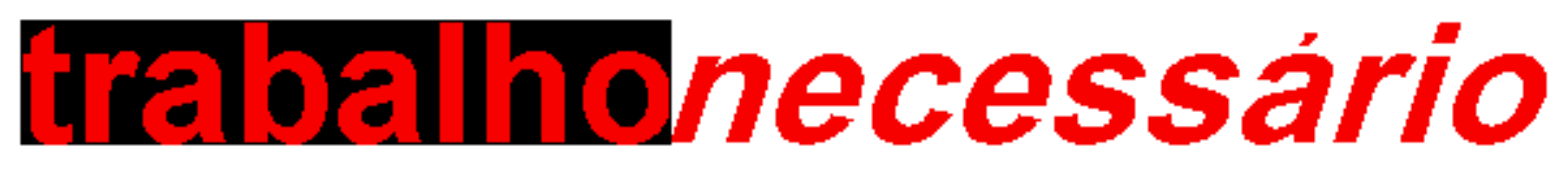

issn: $1808-799 \mathrm{X}$

ano 4 - número 4 - 2006

\title{
O GOVERNO LULA E SUA POLÍTICA (NEOLIBERAL) PARA O ESPORTE [1] NACIONAL. MANUTENÇÃO E/OU ADAPTAÇÃO AO PROJETO DOMINANTE?
}

\section{Adriana Machado Penna*}

Verificamos que entre as estratégias políticas praticadas pelo governo Lula, na busca por reanimar o espírito nacionalista do brasileiro, uma delas apóia-se na utilização dos meios de comunicação que colaboram para a produção e difusão de idéias e atitudes. Neste caso, o espaço televisivo exerce, sem dúvida, papel relevante na construção do senso comum e na sua manutenção. Destacamos, portanto, a insistência por parte do Governo Federal na divulgação de campanhas que valorizam as conquistas esportivas em nosso país e os esforços desempenhados pelos atletas brasileiros, profissionais e amadores.

O uso de imagens e depoimentos de grandes nomes do esporte nacional ou a utilização de exemplos da vida de cidadãos comuns e esportistas anônimos que conseguem alguma forma de destaque perante a sociedade, é exibido como incentivo à competitividade e constante busca pelo sucesso. Reforça-se, assim, a idéia do indivíduo como único responsável por suas vitórias e/ou derrotas no jogo da vida. Força de vontade, elevação da auto-estima, entre outros sentimentos, parecem ser os pré-requisitos para alcançar a superação das diversidades econômicas, sociais e culturais do brasileiro.

Entendemos que o governo, desta maneira, camufla os reais problemas e injustiças experimentadas pelo país. Em nossa concepção, há neste tipo de conduta do Governo Federal a intenção de travar uma relação direta entre a "magia" e aparente unidade e tolerância construídas pela cultura do esporte com a realidade concreta da vida do trabalhador brasileiro.

O Governo Federal busca, assim, sustentar a idéia de que através da valorização do espírito esportivo (competitividade, colaboração, unidade, espírito de grupo, vontade de vencer, etc.) o Brasil poderá estar mais próximo das raias da competitividade internacional, bastando para tanto, um povo de boa vontade que cultive a esperança e que seja, acima de tudo, tolerante.

O interesse no contexto abordado acima, justifica-se no fato de estarmos desenvolvendo uma pesquisa (em andamento), que tem por objeto a análise da realidade concreta da formação do professor de educação física. Portanto, identificar os meios atuais utilizados pelo Conselho Federal de Educação Física (CONFEF) na ingerência 
sobre a formação e atuação dos trabalhadores desta área do conhecimento, caracteriza o objetivo maior de tal pesquisa. Dados levantados até a atual fase de nossa pesquisa, revelam que o CONFEF tem tido voz e voto junto ao Ministério do Esporte, colocando-se como um dos órgãos responsáveis pela elaboração e efetivação de diversos projetos do governo. Tais dados merecerão destaque em nossa pesquisa por entendermos que estes, podem revelar mais uma estratégia do CONFEF para facilitar seu avanço sobre a formação do trabalhador de educação física.

Destacamos, entretanto, que nosso objetivo na elaboração do presente texto, implica em, tão somente, apresentar a análise de documentos[2] que revelam as doutrinas e orientações que têm balizado o Ministério do Esporte na elaboração das Políticas Públicas do Esporte Nacional.

\section{2 _ Política Nacional do Esporte: para que? para quem?}

As políticas do atual Governo Federal são apresentadas e colocadas em prática sob o discurso de que as mesmas visam beneficiar a todos os brasileiros, em especial os que estão, socialmente e economicamente excluídos. Além desses aspectos, o governo defende que os negócios que envolvem o esporte devem ser encarados como um setor com amplas capacidades de geração de lucros e que, por este motivo, trata-se de um mercado a ser explorado com maior atenção.

Além de fazer bem a saúde, o esporte também faz muito bem para a economia do País. A indústria esportiva brasileira movimenta mais de $\mathrm{R} \$ 25$ bilhões por ano. O setor também é um importante gerador de emprego e hoje são 300 mil pessoas que dependem economicamente da atividade esportiva no Brasil. (BRASÍLIA, 18/06/2004)

No que tange as políticas nacionais do esporte, o governo brasileiro vem pautando suas ações, baseando-se nas orientações de um documento produzido e divulgado pela ONU[3].O Ministério do Esporte defende que o caráter que pretende dar à estrutura de sua Política de Esporte Nacional, trará repercussão para contensão das diferenças sociais, dos diversos desajustes de comportamentos que possam gerar embates e acirramento de idéias, além de ser capaz de conter a exclusão social e a miséria.

De acordo com informações da Ascom/ME (21/06/2004), órgão responsável por veicular notícias referentes ao Ministério do Esporte, o presidente Lula fez um discurso durante a abertura da 1a Conferência Nacional do Esporte[4], destacando a importância do programa Segundo Tempo e afirmando[5] que: " o eixo central da política de esporte é a escola." (BRASÍLIA, 16/06/2004, grifo nosso).

O segundo tempo é um programa do Ministério do Esporte, em parceria com o Ministério da Educação promovido pela Secretaria de Esporte Educacional que assegura a 750 mil jovens carentes através de parcerias, a alimentação, uniforme e material esportivo, reforço escolar, noções de saúde, higiene. As atividades acontecem em horário oposto ao turno escolar e são acompanhadas por um coordenador (professor de Educação Física) e quatro (monitores) disponibilizados pelo Ministério, em cada núcleo implantado.

Na mesma oportunidade, o presidente Lula ressaltou "a importância do esporte na formação do povo brasileiro". Segundo Nádia Faggiani, repórter da Agência do Brasil de comunicação, o presidente Luiz Inácio Lula da Silva afirmou que "junto com a educação, o esporte é a forma mais barata e importante de combater os males que tomam conta da 
juventude brasileira, como o uso de drogas, a criminalidade e a evasão escolar." O presidente, ainda, tornou pública sua concepção sobre como o esporte deverá orientar as políticas nacionais, esclarecendo que:

'Queremos fazer do esporte em nosso país uma política tão comum como escovar os dentes. Desde a fase da disputa eleitoral, assumi o esporte como instrumento fundamental do povo e o compromisso de que era preciso criar um Ministério do Esporte no Brasil, separado do turismo que é hoje um setor gerador de grande fonte de renda. O papel do Ministério do Esporte hoje é o de fazer desabrochar milhares de talentos que temos no setor. ' (ibid.)

A Conferência Nacional do Esporte, além de tratar de muitos temas ligados ao setor esportivo, também dedicou um espaço específico para discutir a formação profissional. Uma das sugestões "prevê a parceria dos Governos com a iniciativa privada, visando o financiamento de pesquisa e a manutenção de laboratórios didático-pedagógicos." Neste debate estiveram reunidos pesquisadores de todo o país, ligados ao campo da educação física, entre outros. Entre muitas questões levantadas, os pesquisadores presentes ressaltaram a importância da $1^{\underline{a}}$ Conferência Nacional do Esporte contar com um apoio interministerial e que, neste sentido, a proximidade com o Ministério da Educação foi considerada uma ação positiva, já que: "O vínculo com a Educação favorecerá a otimização de recursos destinados aos cursos de educação física e mudanças nos currículos dos cursos de educação física, por exemplo." (BRASÍLIA, 18/06/2004, grifo nosso).

Vale a lembrança de que o CONFEF fez parte da Comissão Organizadora da $1^{\text {a }}$ Conferência Nacional do Esporte, sendo, portanto, interlocutor em todos os debates promovidos, durante os quatro meses (de março a abril) de conferências estaduais e municipais, levando seus interesses e reivindicações à 1aㅡ Conferência Nacional, realizada em Brasília, entre 17 e 20 de junho. O CONFEF teve participação efetiva nas várias etapas de discussões que aconteceram em todo o país, buscando ampliar seu campo de ingerência.

Foi eleito como central em uma das etapas preliminares à $1^{\text {a }}$ Conferência Nacional do Esporte (Conferência IX, 18/06/2004), o seguinte tema: "Escolas têm papel essencial na prática esportiva". Segundo o Secretário Nacional do Esporte Educacional, Ricardo Leyser, ' a escola tem papel central para a democratização do esporte e ampliação da base.' Outros integrantes do evento foram ouvidos, como no caso do presidente da Comissão de Ética do Conselho Federal de Educação Física (CONFEF), João Batista Tojal, que defendeu a criação de uma política nacional para o esporte onde a mesma deve "preservar o caráter formativo dos estudantes e deve se basear em princípios como cultura, participação, cooperação, (...),responsabilidade social e ética."

3 _ Orientação dos organismos interacionais para a elaboração da Política Nacional do Esporte no Brasil

Nos interessa neste ponto, identificar as orientações feitas por organismos multilaterais, do âmbito da ONU, UNESCO, BM e FMI, que junto ao financiamento de projetos econômicos, se voltam para projetos envolvendo "o setor social, como medida de alívio e de redução da pobreza (...)”. (FONSECA, p. 169, 2000). Tais medidas sinalizam 
para uma emergência em se descaracterizar o significado da miséria, da desigualdade social e da perda da dignidade humana, objetivadas em conseqüência da intensificação da exploração capitalista.

Neste sentido, a ONU, em julho de 2003, publica um documento intitulado:

"Relatório da Força Tarefa entre Agências das Nações Unidas sobre o Esporte para - Desenvolvimento e a Paz: em Direção à Realização das Metas de Desenvolvimento do Milênio". A elaboração deste documento inicia-se com a constituição de uma Força Tarefa entre Agências da ONU "para rever as atividades que envolvem o esporte dentro do sistema das Nações Unidas”. (BRASíLIA. Ministério dos Esportes, 2004).

A idéia central do relatório, concentra-se em uma análise das inúmeras contribuições que o esporte pode oferecer para a concretização das Metas de Desenvolvimento para o Milênio (MDMs) e que, para tanto: "Os esforços das Nações Unidas no sentido de prestar assistência a diferentes países para que consigam as MDMs incluem vários atores que trabalham em parceria para o desenvolvimento sustentável e a paz." (ibid.).

Este documento utiliza-se do princípio da igualdade e da participação de todos nos benefícios sociais sem, em momento algum, identificar qualquer contradição entre classes sociais, raça, religião, cultura, poder econômico, etc. Nesse sentido, o esporte é tratado como um instrumento compensatório capaz de _ desligado da totalidade das relações sociais _ facilitar a inclusão, sobretudo, de pobrēes, mulheres, crianças e todos aqueles considerados à margem da sociedade. Ao tratar da relação do esporte com o desenvolvimento humano, o documento destaca que:

Um ponto fundamental da noção de desenvolvimento das Nações Unidas é o desenvolvimento humano sustentável, que reconhece que o desenvolvimento vai muito além do crescimento econômico. O desenvolvimento é um processo de ampliação das escolhas das pessoas e de aumento de oportunidades disponíveis a todos os membros da sociedade. Baseado nos princípios da inclusão, da eqüidade e da sustentabilidade, a ênfase está na importância de aumentar a oportunidade para a geração atual assim como as de gerações futuras. As capacidades humanas básicas necessárias para isto são: ' conduzir vidas longas e saudáveis, ter acesso ao conhecimento, ter acesso aos recursos necessários para manter um padrão de vida decente e poder participar na vida da comunidade' [6]. O esporte pode ajudar diretamente a construir essas capacidades. (ibid., grifo nosso).

Mediante uma visão liberal de valorização do indivíduo, o Relatório da ONU entende por esporte: "todas as formas de atividade física que contribuam para a boa forma física, para o bem-estar mental e para a integração social." (ibid.).

Diante desta visão, o ser humano funciona como um mero instrumento às demandas do sistema. O homem, neste sentido, não é respeitado como produto de sua história e ator principal na mesma. O que se percebe, em todo o conteúdo do documento, é um argumento de reforço permanente dos ideais da doutrina liberal e o constante fortalecimento de valores individualistas, marcantes nas relações humanas produzidas na atualidade. Apoiado nestes princípios o Relatório em questão alega que o esporte, por ser "uma ferramenta eficaz para a mobilização social", é capaz de exercer influência sobre a saúde, reduzindo a probabilidade de doenças, através da mobilização social. Além deste 
aspecto, o Relatório sinaliza para o potencial econômico significativo contido no esporte, afirmando ser este um importante setor para a geração de empregos. "É também um ambiente-chave e uma atração natural para a participação de voluntários. Além, disso, a prática de esporte apóia a preservação de um meio ambiente limpo e saudável”. (ibid.)

Dado que é um local-chave para a participação voluntária, o esporte deve ser usado para promover o voluntariado, especialmente entre os jovens cuja participação é um forte indicativo do voluntariado em sua vida futura. $\mathrm{O}$ voluntariado fornece benefícios ao indivíduo, tais como a auto-satisfação, a aquisição de habilidades, o aumento da compreensão e a integração social. Beneficia-se também a sociedade, com impactos que incluem o crescimento econômico, o bem-estar social, a participação comunitária, a geração de confiança recíproca e a ampliação da interação social através de novas redes a construir e consolidar a coesão e estabilidade sociais. $O$ esporte é uma maneira importante de incentivar o voluntariado nas sociedades e de se alcançar os benefícios sociais resultantes.

É, portanto, valendo-se desta visão positivista e funcionalista, que o Relatório trata o esporte como uma ferramenta viável ao projeto dominante. As contradições vividas no seio das relações sociais assumem, neste contexto, uma aparência harmônica.

O esporte pode atravessar as barreiras que dividem as sociedades, tornando-o assim uma poderosa ferramenta para apoiar esforços de prevenção de conflitos e de construção da paz, tanto simbolicamente no nível global, quanto de maneira bastante prática dentro das comunidades. Quando aplicados eficazmente, os programas de esportes promovem a integração social e fomentam a tolerância, ajudando reduzir a tensão e gerar diálogo. O poder de organização e reunião do esporte o torna uma ferramenta ainda mais eficaz para a comunicação e a conscientização. (ibid., grifos nossos)

Seguindo nesta linha, a Força Tarefa da ONU "recomenda fortemente" que os países membros das Nações Unidas, se engajem na implantação deste programa, chamando a atenção para as seguintes questões:

"1. O esporte deve ser bem integrado na agenda do desenvolvimento. 2. O esporte deve ser incorporado como uma ferramenta útil nos programas para o desenvolvimento e a paz. 3. As iniciativas baseadas no esporte devem ser incluídas nos programas de país das Agências das Nações Unidas, conforme, apropriado e de acordo com necessidades localmente avaliadas. 4. Programas que promovem o esporte para o desenvolvimento e a paz necessitam de mais atenção e recursos por parte dos Governos e sistema das Nações Unidas. 5. As atividades baseadas na comunicação que utilizam o esporte devem focalizar na mobilização social e na conscientização bem-direcionados, particularmente nos níveis nacional e local. 6 . Uma recomendação final da Força Tarefa é que a maneira mais eficaz de implementar os programas que usam o esporte para o desenvolvimento e a 


\section{paz é através de parcerias. (ibid., grifo nosso}

O desenvolvimento econômico é, na concepção do Relatório, um dos pontos que deve ser mais explorado, tanto pelas Nações Unidas como pelos seus "parceiros", incentivando-os a integrar o esporte em suas ações políticas. Este documento reforça, porém, que além dos interesses econômicos, é necessário intensificar a utilização das atividades esportivas como conquista de qualidade de vida, prevenção de doenças e integração social. Portanto, o que se esconde por trás de tais ações, acaba por revelar o seu maior objetivo, que consiste em potencializar a força de trabalho.

O potencial econômico do esporte é destacado por seu peso econômico resultante de atividades tais como a fabricação de produtos esportivos, eventos desportivos, serviços relacionados ao esporte e a mídia. (...) Além de ser uma força econômica em si, o esporte é também um potencial catalisador para o desenvolvimento econômico. Uma população fisicamente ativa é uma população mais saudável, melhorando a produtividade da força de trabalho e aumentando os resultados econômicos. $O$ esporte e a atividade física propiciam também uma das formas mais custo-efetivas de medicina preventiva, com potencial para reduzir drasticamente os custos com a saúde. (ibid., grifo nosso)

O texto do relatório, ao tratar do tema específico "Esporte e Educação", insiste que a educação é uma medida fundamental para a "concretização de todas as Metas de Desenvolvimento do Milênio" e que, por sua vez, "o esporte tem um lugar natural na educação, seja como uma abordagem formal, não-formal ou informal." Ainda, ao tratar do tema Educação, o relatório se refere à educação física escolar como "um componentechave de uma educação de qualidade e pode ser utilizada para promover a educação entre os jovens." O documento afirma, ainda, que o esporte é uma 'escola para a vida', ensinando valores básicos e habilidades que contribuem para o desenvolvimento do indivíduo. Garante que tais habilidades, aprendidas através "da brincadeira, da educação física e do esporte são fundamentais para o desenvolvimento holístico dos jovens". Afirma, também, que o aprendizado de tais habilidades "como a cooperação e a auto-confiança, são essenciais para a coesão social e são levadas para a vida adulta."

Ao tratar, especificamente, da relação entre "Esporte, Educação e Educação Física", diz que esta última é essencial para uma educação de qualidade. Chama a atenção para o fato de que:

Negligenciar a educação física reduz a qualidade da educação, com futuros impactos negativos na saúde pública e nos orçamentos da saúde. A educação física é a única matéria no currículo escolar que focaliza especificamente o corpo.

Dessa forma, ajuda a ensinar aos jovens o respeito com o corpo _ seus próprios, assim como os dos outros _ e os ajuda a lidar com muitos dos desafios enfrentados por jovens, incluindo o risco do HIV/AIDS e outras doenças sexualmente transmitidas e os perigos do tabaco e das drogas.

O Relatório apresenta, também, alguns resultados de pesquisas realizadas no meio escolar, que demonstraram as "correlações positivas entre a prática de esporte e a realização acadêmica". Diz ainda, que segundo o resultado das pesquisas: "aumentar o tempo utilizado na educação física nas escolas não reduz as notas em matérias 
intelectuais, mas melhora para alguns alunos a capacidade de aprender e reter informação". Entre as principais considerações do relatório, a respeito do esporte e da educação, uma nos chamou atenção:

Devido ao futuro impacto negativo na saúde pública e nos orçamentos da saúde resultantes da negligência em relação à educação física, os Governos devem reconhecer a importância da educação física e demonstrar seu apoio melhorando a provisão de recursos, de treinamento da equipe de funcionários e alocando quantidades apropriadas de tempo escolar para a educação física.

É visível a defesa pelo acréscimo de tempo dedicado à educação física escolar, porém, tal defesa caracteriza-se em oposição à luta por uma educação física progressista, que contribua com transformações significativas no campo educacional; que se entenda parte de uma totalidade, influenciando, desta forma, a dinâmica social a qual pertence e fazendo da ação educativa, antes de tudo, uma ação política. (Vitor Oliveira Marinho, 1987)

O governo Lula tem sido alvo de inúmeras críticas em função da sua subserviência ao capital estrangeiro e às orientações dos organismos internacionais. Estas são medidas que, para a crítica, provoca o aprofundamento e avanço das políticas neoliberais.

É, portanto, diante de tamanha adequação às políticas neoliberais que o país tem pautado suas políticas de incentivo ao esporte nacional e, sobretudo, ao esporte escolar e a educação física escolar.

Ao analisarmos os documentos[7] que divulgam as medidas elaboradas pelo Ministério do Esporte, não restam dúvidas que, na área do esporte, o Governo Federal vem buscando uma base para a construção "Política Nacional do Esporte", enfatizando seu ineditismo no país. Reforça ainda, que tais políticas "abrangem todos os tipos de esporte, da recreação à competição, e visam o benefício de todos os brasileiros, em especial os social e economicamente excluídos." (BRASÍLIA, 03/11/2004)

Ainda, no mesmo documento, o Ministério do Esporte destaca a publicação do Relatório da ONU e faz a seguinte observação: "E é impressionante ver a sintonia que existe entre o que já estamos fazendo aqui no Brasil e o que propõe a ONU."

Sobre o Relatório produzido pela ONU, o Ministério do Esporte acrescenta que: "Recentemente, o secretário-geral das Nações Unidas, Kofi Annan, divulgou um documento intitulado Esporte para o Desenvolvimento e a Paz. É um relatório que faz uma análise da situação do esporte no mundo e propõe ações práticas para os governos." A partir destas observações, o documento do Ministério do Esporte, passa a discorrer sobre as semelhanças entre as metas traçadas pelo relatório da ONU e as políticas para o esporte nacional:

1.Esporte social- instrumentos de inclusão social (em todos os tipos de esporte, há o fator inclusão social, mas há, também, uma política específica para isto); 2. Esporte Educacional - complemento à atividade escolar (política global, que envolve o esporte além da disciplina Educação Física, e a revitalização dos jogos estudantis e universitários); 3. Esporte de alto rendimento - o esporte competitivo (com o esporte para milhões, produziremos muitos atletas - e estes servem de exemplo para a prática de esporte por milhões); e 4. Recreação e Lazer - Esporte como qualidade de vida: saúde e bem-estar físico e psicológico (incentivo à prática esportiva para todos, como parte do cotidiano) 
(ibid.)

O Ministro do Esporte ressalta que o esporte é capaz de introduzir nas crianças valores como a "solidariedade, o respeito ao próximo, a tolerância, o sentido coletivo e a cooperação." Além dessas qualidades, outras como "vida saudável, capacidade de liderança, disciplina, respeito às regras, noções de trabalho coletivo", também merecem destaque no discurso do Ministro. Afirma, ainda, que o desenvolvimento desta política é capaz de incluir socialmente "32 milhões de crianças" pobres, pois, sempre lhes foi negado o acesso de esporte e lazer.

Identificamos em tais propostas que o esporte continua sendo tomado como um instrumento desconectado de todo o contexto social, político e econômico do país. A ele é dada a incumbência de "ser o caminho mais rápido para a inclusão social dessas populações." (ibid.).

No que tange o Esporte na Escola, destaca o Programa Segundo Tempo esclarecendo que este prevê um horário adicional na escola, ocupado com atividades esportivas, "sob a orientação de uma enorme rede de professores de educação física e monitores estagiários, treinados e contratados para este fim." (ibid., grifo nosso).

O Ministério do Esporte conta com a parceria de várias instituições para a execução do Programa Segundo Tempo, entre eles estão os Ministérios

da Educação, da Segurança Alimentar, da Defesa, do Trabalho e da Assistência Social. Participam dele, também empresa, clubes sociais e esportivos, ONGs, universidades,as Forças Armadas, os governos estaduais e municipais, o Corpo de Bombeiros e policias, sindicatos e associações profissionais.

O tema "Fator de desenvolvimento econômico" é tratado pelo Ministério do Esporte (BRASÍLIA, 03/11/04) como uma questão relevante, pois defende a idéia de que ao redor do setor da economia ligado às atividades esportivas, funciona uma "dinâmica econômica" com capacidade de gerar emprego e renda no mundo inteiro. Segundo o Ministério, graças a esta "dinâmica", presente na economia brasileira, milhares de pessoas no país estão empregadas, direta ou indiretamente.

Ressalta, também, a importância de se trazer para o país grandes eventos esportivos e cita o exemplo dos Jogos Pan-americanos de 2007, que acontecerão no Rio de Janeiro. Chama a atenção para o fato de que estes eventos, "movimentam vultosas somas em obras físicas (...), para cumprir exigências internacionais", além de abrir milhares de vagas de "empregos temporários". Segundo o Ministério do Esporte, existem outras questões que, somadas as anteriores, são relevantes para o crescimento econômico do país:

\begin{abstract}
Além de sua brutal importância como fator de desenvolvimento humano, o esporte também ganha cada vez mais relevância no desenvolvimento econômico. A começar pelo fato de que um trabalhador que pratica algum esporte ou atividade física terá uma saúde melhor, um humor melhor e, com isso, renderá mais em seu trabalho. Se isso se estender a milhões, o efeito na produtividade do país será rapidamente sentido. (ibid., grifo nosso)
\end{abstract}

A $1^{\text {a }}$ Conferência Nacional do Esporte teve por principal objetivo, segundo o 
Ministério do Esporte, "debater o esporte como política pública de inclusão social" e que, segundo as afirmações do Ministro Agnelo Queiroz, a escola é o eixo central da política do esporte nacional. (BRASÍLIA, 17/06/2004).

Retornando ao Relatório da ONU, identificamos dentre suas orientações, uma que vem sendo seguida pelo Governo Federal amplamente. Ao tratar especificamente sobre Esporte e Comunicação, a ONU afirma que:

O esporte é uma das ferramentas de comunicação mais poderosas do mundo devido à seu apelo quase universal, seu poder de união e suas diversas associações positivas. Juntas, estas características conferem ao esporte a capacidade de alcançar diversos públicos de várias maneiras, particularmente os grupos que geralmente são difíceis de alcançar de outro modo. Sozinho, o esporte tem a habilidade de comunicar mensagens como da cooperação, convivência, ou como administrar com dignidade a vitória e a derrota. Como um canal poderoso para comunicar mensagens, o esporte também pode ser uma arena para promover os objetivos das Nações Unidas para o desenvolvimento e a paz. Seja num único evento ou numa campanha de longo prazo, o esporte oferece oportunidades valiosas para a conscientização e a mobilização das comunidades. (grifo nosso)

Ao destacarmos as orientações acima, é impossível não lembrarmos do episódio, à época da deposição do presidente do Haiti, Jean-Bertrand Aristide, exilado em fevereiro de 2004, quando o Brasil enviou tropas militares que iriam integrar as Forças de Paz da ONU no Haiti. Este foi um evento amplamente divulgado pelos meios de comunicação no Brasil, sobretudo, durante o jogo de futebol realizado naquele país, que teve, segundo o governo brasileiro, o objetivo de fortalecer a paz e a amizade entre Brasil e Haiti, além de elevar a auto-estima daquele povo.

Nesta oportunidade, o presidente Lula disse estar confiante na missão que coube às Forças Amadas brasileiras de "levar a paz e restabelecer a democracia naquele país." Além das ações de controle e policiamento, as tropas brasileiras também participaram de ações sociais junto às comunidades haitianas. Essas ações eram compostas, prioritariamente, de atividades desportivas, sendo utilizado um grande número de materiais esportivos doados pelo Ministério do Esporte do Brasil.

De acordo com Ministro do Esporte, Agnelo Queiroz, está ação consistia de grande validade, já que: "o esporte é um excelente instrumento de promoção da paz e do desenvolvimento humano". (...) nossos soldados estão resgatando fundamentos da ONU e do governo brasileiro que utilizam 0 esporte na formulação de políticas sociais." (MINISTÉRIO DO ESPORTE, 31/05/2004)

Por fim, mas não esgotando a riqueza e relevância dos documentos que contribuíram para a produção deste texto, foi possível perceber que o atual governo brasileiro vem se adequando ao modelo de sociedade neoliberal e ao projeto de formação humana proposto pelo pensamento hegemônico. Pensamento este que tem a pretensão de considerar-se único, inquestionável e insuperável.

\section{Referências Bibliográficas}

BRASÍLIA. MINISTÉRIO DO ESPORTE. UMA POLÍTICA NACIONAL DE ESPORTE. Disponível em: http//:www.esport.gov.br/boletim_política_nacional.asp Acesso em: 05/12/2004

MINISTÉRIO DO ESPORTE. Notícias. Disponível em: 
http//www.esporte.gov.br/conferencianacional/noticia_detalhe.asp?id_noticia=2229

FONSECA, Marília. O banco mundial e a educação. Reflexões sobre o caso brasileiro. In: (org.) GENTILI, Pablo. Pedagogia da exclusão. Crítica ao neoliberalismo em educação. 7aa ed. Vozes. Petrópolis. 2000.

OLIVEIRA, Vitor Marinho de. Tudo tem a ver com tudo ou Apresentação. In: OLIVEIRA, Vitor Marinho de (org.). Fundamentos pedagógicos. Educação Física. Rio de Janeiro: Ao livro técnico, 1987.

ORGANIZAÇÃO DAS NAÇÕES UNIDAS. Relatório da Força Tarefa entre Agências das Nações Unidas sobre o Esporte para o Desenvolvimento e a Paz: Em direção às Metas de Desenvolvimento do Milênio. 2003. Disponível em: http://wwwesporte.gov.br. Acesso em: $15 / 11 / 2004$.

$\left({ }^{*}\right)$ Mestre em Educação

[1] Texto apresentado no XIV Congresso Brasileiro de Ciências do Esporte - I Congresso Internacional de Ciências do Esporte, que aconteceu entre os dias 04 e 09 de setembro de 2005, na Universidade Federal do Rio Grande do Sul (UFRGS), Porto Alegre _ RS.

[2] Relatório da Força Tarefa entre Agências das Nações Unidas sobre o esporte para o Desenvolvimento e a Paz: em direção à realização das Metas de Desenvolvimento do Milênio (ONU, 2003);

MINISTÉRIO DO ESPORTE: uma Política Nacional de Esporte (BRASIL, 2004).

[3] Vide rodapé ํㅜ 2

[4] Segundo o Ministério do Esporte, o objetivo da 1ª Conferência Nacional do Esporte foi: "promover uma discussão nacional para discutir o aprimoramento da política pública de promoção da atividade esportiva no país." (BRASílIA,10/03/2004). Este evento foi organizado durante quatro meses (de março a junho de 2004), onde aconteceram palestras, debates e fóruns em etapas municipais, estaduais, no Distrito Federal e por último, culminando na 1르 Conferência Nacional do Esporte, realizada em Brasília de 17 a 20 de junho.

[5] Segundo informa o Ministério do Esporte, sobre o Programa Segundo Tempo: "Trata-se de uma enorme parceria, um verdadeiro pacto nacional pelo desenvolvimento humano de nossas crianças, por meio do esporte.(...) Sua finalidade é, em primeiro lugar, democratizar o acesso à prática esportiva. Além de estender a permanência da criança e do adolescente na escola, possibilitando o seu desenvolvimento integral."

[6] PNDU (2002) United Nations Human Developement Report, p. 13.

[7] Vide nota de rodapé $n^{\circ} 2$

file://C: Documents and Settings\AdministradorlMeus documentos\Minhas Webs\NED... 4/9/2008 